\title{
Institutional Anticoagulation Protocol for Septic DIC is Associated with Differences in In-Hospital Mortality. J-SEPTIC DIC STUDY (A Nationwide Registry Study)
}

Keiko Tanaka

Ehime University

Hironori Matsumoto

Ehime University

Muneaki Ohshita

Ehime University

Suguru Annen

Ehime University

Yuki Nakabayashi

Ehime University

Mayuki Aibiki ( $\square$ aibiki@m.ehime-u.ac.jp)

Hito Medical Center https://orcid.org/0000-0001-5699-5316

\section{Research}

Keywords: Anti-coagulation therapy, APACHE II score, Institutional difference, Septic disseminated intravascular coagulation

Posted Date: August 25th, 2020

DOI: https://doi.org/10.21203/rs.3.rs-58689/v1

License: (9) This work is licensed under a Creative Commons Attribution 4.0 International License. Read Full License 


\section{Abstract}

Background: We analyzed data from Japanese nationwide registry study of severe sepsis/septic shock to determine the influence of institutional treatment protocol, which has not been evaluated, on in-hospital mortality rate in septic DIC.

Methods: From among all sepsis patients $(n=3193)$, we selected those $(n=1856)$ diagnosed with DIC according to the JAAM criteria, then divided them into three groups depending on DIC treatment protocol: patients admitted to hospitals providing basically no anti-coagulation therapy (NO-TX group: $n=287$ ); those admitted to hospitals routinely providing such treatment (anti-thrombin concentrate and/or rhthrombomodulin or other anti-coagulants such as heparin/heparinoids: DO-TX group: $n=1202$ ); and those admitted to hospitals providing treatment at the discretion of the physician-in-charge (DEP-TX group: $n=446)$.

Results: In DIC patients only, in-hospital mortality was much higher in the NO-TX group (46.2\%) than in the DO-TX group (34.1\%) despite comparable APACHE II scores. The hazard ratio (HR) of mortality was much lower in the DO-TX group $(0.76,95 \% \mathrm{Cl}: 0.61-0.96)$ than in the NO-TX group (set at 1.0). When nonDIC subjects whose records contained complete information on JAAM and ISTH scores were also included ( $n=2513)$, however, different treatment protocols were no longer associated with differences in HR. Nevertheless, in-hospital mortality rates still differed among the three groups even after non-DIC patients were included.

Conclusions: Thus, the present results support the use of anti-coagulation treatments for septic DIC and suggest that outcomes are affected by other institutional factors besides anti-coagulation protocol, such as an institutional approach to sepsis. The mechanisms underlying this effect should be clarified.

\section{Background}

Although numerous studies using animal models have supported anti-coagulation treatments for septic DIC (1), such interventions against DIC are actually implemented in clinical settings in only a very few countries. Although Japan is one of these countries, even in Japan there are certain institutions that do not routinely perform anti-coagulation treatments in keeping with the Surviving Sepsis Campaign Guidelines (2). This unique situation, in which some institutions perform anti-coagulation treatments while others do not, enables us to evaluate the effects of anti-coagulation treatments in patients with septic DIC in the clinical setting. For this reason, we previously conducted a nationwide registry study called the Japan Septic DIC study (J-SEPTIC DIC Study) (3).

Japan's unique situation has enabled us to develop a working hypothesis regarding the impact of anticoagulation treatments. Japan's hospitals can be classified into three types according to their institutional protocols for septic DIC therapy: hospitals that typically do not perform anti-coagulation treatments for septic DIC (NO-TX); hospitals that perform such treatments routinely (DO-TX); and hospitals that perform such treatments at the discretion of the physician-in-charge (DEP-TX). In this 
study, using the database from the J-SEPTIC DIC Study (4), we examined the association of the three types of the institutional treatment protocols for septic DIC with in-hospital mortality rates (HMR) in 3193 patients with severe sepsis/septic shock.

\section{Methods}

The J-SEPTIC DIC Study was conducted at 42 intensive care units (ICUs) in 40 institutions in Japan. The Institutional Review Board of each hospital approved the study, and the need for informed consent was waived due to the study's retrospective nature.

\section{Patient selection and data collection}

Consecutive patients admitted to the ICU for the treatment of severe sepsis/septic shock between January 2011 and December 2013 were registered in the J-SEPTIC DIC Study through the University Hospital Medical Information Network Clinical Trial Registry (UMIN-CTR ID: UMIN000012543). A new sepsis definition was adopted in 2016 (5), but due to the timing of this study, we used the definitions of severe sepsis/septic shock issued by the International Sepsis Definitions Conference in 2001 (6). Patients who were younger than 16 years of age and those who developed severe sepsis/septic shock after admission to the ICU were excluded.

The following data were collected: age; sex; body weight; admission route to the ICU; pre-existing organ dysfunction; pre-existing hemostatic disorder; Acute Physiology and Chronic Health Evaluation (APACHE) II score (7); Sequential Organ Failure Assessment (SOFA) score (8) (days 1, 3, and 7); systemic inflammatory response syndrome (SIRS) score (9) (days 1, 3, and 7); primary infection site; blood culture results; microorganisms responsible for the sepsis; daily results of laboratory tests during the first week after ICU admission; lactate levels (days 1, 3, and 7); administration of drugs during the first week after ICU admission, including anti-DIC drugs, other anticoagulants, immunoglobulins, and low-dose steroids; number of transfusions and bleeding complications during the first week after ICU admission; therapeutic interventions, including surgical interventions at the infection site, renal replacement therapy, renal replacement therapy for non-renal indications, polymyxin B direct hemoperfusion, extracorporeal membrane oxygenation, and intra-aortic balloon pumping during the first week after ICU admission; durations of ICU stay and hospital stay; and outcomes in the ICU and hospital.

The DIC score was calculated according to one scoring algorithm based on the Japanese Association for Acute Medicine (JAAM) DIC criteria (10) and another based on the International Society of Thrombosis and Hemostasis (ISTH) criteria (11).

Of the 3195 patients registered in the J-SEPTIC DIC study, two patients were excluded because of missing data on APACHE II score or illogical data on the duration of hospital stay. Thus, data on 3193 patients were available for analysis. Of those patients, 1856 and 1089 were diagnosed with DIC according to the JAAM and ISTH criteria (overt DIC), respectively. In this study, we selected patients whose records contained complete information on JAAM and ISTH (International Society of Thrombosis and 
Hemostasis) scores. Even non-DIC subjects ( $\mathrm{n}=2513)$ were required to have this information. As a result, the number of patients in each DIC criteria category differs from that in our previous paper using the same database (12).

\section{Statistical analysis}

Patients were divided into three groups based on the treatment protocol for DIC at the hospital where they were admitted: hospitals that typically provided no anti-coagulation therapy (NO-TX group), hospitals that routinely provided anti-coagulation treatments (anti-thrombin concentrate and/or rh-thrombomodulin, or other coagulants: heparins/heparinoid or serine protease inhibitors: DO-TX group), and hospitals that provided such treatments at the discretion of the physician-in-charge (DEP-TX group). To analyze adjusted hazard ratios, we selected the following potential confounding factors a priori: sex, age, changes in SOFA, APACHE II score, site of infection, basal diseases, continuous hemodiafiltration (CHDF), hemostatic abnormality, treatment for original infection, ventilator application, blood purification, vasopressor use, occurrence of intracranial hemorrhage, transfusion requirements related to bleeding, and bleeding requiring surgical intervention.

Cox proportional hazards models were used to estimate the hazard ratios (HRs) and 95\% confidence intervals (Cls) for the in-hospital mortality rate (HMR). Patients contributed person-days from their day of ICU admission until their day of death or day of discharge, whichever came first. All statistical analyses were performed using SAS software package version 9.4 (SAS Institute, Inc., Cary, NC, USA).

\section{Results}

3193 cases with severe sepsis/septic shock were included (two patients were excluded because of incomplete records). DIC was diagnosed according to both the JAAM criteria and the ISTH criteria. There were no differences in demographic data, such as sex, age, changes in SOFA and APACHE II score among the three groups classified according to hospital treatment protocol for DIC (Table 1). Table 2 shows the rates at which anti-coagulation therapy was administered to all patients including non-DIC patients, DIC patients who were diagnosed according to the JAAM criteria (JAAM-DIC patients) and DIC patients who were diagnosed according to the ISTH-DIC criteria (ISTH-DIC patients).

Among the JAAM-DIC patients, HMRs in the NO-TX group ( $n=208)$, DO-TX group ( $n=1202)$, and DEP-TX group ( $n=446$ ) were $46.2 \%, 34.1 \%$ and $38.6 \%$, respectively. The treatment groups thus had different HMRs although they had no differences in disease severity as assessed by APACHE II scores (the middle panel of Table 3). Even when patients without DIC were included ( $n=2513)$, although the three groups had similar APACHE II scores, they had different in-hospital mortality rates (the upper panel of Table 3), suggesting that additional factors other than anti-coagulation treatment protocol were affecting the outcomes. However, compared with the NO-TX group, the DO-TX group was associated with reduced risk of HMR: the adjusted hazard ratios (HRs) in the DO-TX group were 0.76, 95\% Cl: 0.60 - 0.96 among JAAMDIC patients and $0.70,95 \% \mathrm{Cl}$ : 0.52-0.95 among ISTH-DIC patients. When non-DIC patients were included, however, no adjusted HR differences were found among the groups (Table 4). 


\section{Discussion}

\section{Differences in institutional treatment protocol for septic DIC}

In Japan, medical institutions can be classified into three groups according to their policies on the administration of anti-septic DIC therapies, which generally consist of anti-coagulants such as rh-TM and/or AT concentrates: 1) the NO-TX group: hospitals that typically do not provide anti-coagulation treatment for septic DIC, a policy that is considered valid not simply because infection management is expected to relieve sepsis even in the case of septic multi-organ system failure (MOF) but also because it is in keeping with the Surviving Sepsis Campaign Guidelines (2), 2) the DO-TX group: hospitals that routinely provide anti-coagulation therapies to improve MOF in septic DIC patients, and 3) the DEP-TX group: hospitals that provide such treatments at the discretion of the physician-in-charge, which means that these hospitals occupy an intermediate position between the other two extremes in terms of the rate at which they administer anti-coagulation therapies. In this study, we have clearly shown that differences in institutional policies regarding the administration of anti-coagulation treatments for septic DIC, are associated with differences in in-hospital mortality rate (HMR) and in adjusted HRs of HMR, especially between the DO-TX and NO-TX groups of patients with septic DIC. This finding appears to support the use of anticoagulants such as rh-TM or AT concentrates (12) for septic DIC with MOF.

International differences in in-hospital mortality rates of patients with septic DIC

Septic DIC is a specific pathology resulting from hypercoagulation followed by prolonged anti-fibrinolysis, which leads to multiple organ failure due to impairment of microcirculation related to the formation of microthrombi (1). Treating the initial infection is a requisite step in the treatment of sepsis, and should be done in parallel with other standard therapies including respiratory, hemodynamic, and nutritional management (13). Together, these therapeutic strategies are recommended globally as "bundle therapy for severe sepsis." Despite a report of improvement in the survival rate among severe sepsis patients after the implementation of bundle therapy (14), the mortality rate among these patients remains less than optimal. As another aspect, the outcomes of sepsis cases can be considerably worsened when disseminated intravascular coagulation occurs (15). Therefore, we need additional therapeutic interventions such as anti-coagulation treatments for severe sepsis with DIC. Such treatments have been administered in Japan, usually in the form of rh-TM and/or AT III concentrates $(3,12)$, but have not been used in clinical settings in Western countries. Furthermore, interestingly, the use of AT III is even prohibited by the Surviving Sepsis Campaigning Guidelines 2016 (16). North and South America and certain European countries have reported improvements in the mortality rate associated with severe sepsis/septic shock in the past decade (17), yet even their improved mortality rates are markedly worse than those reported in a Japanese Registry Study when mortality is considered according to the number of affected organs (18). The rate of hospital mortality in Western countries remains almost double that in Japan: when one organ is affected, there is a $27 \%$ hospital mortality rate in Western countries compared to a $13 \%$ rate in Japan; when two organs are affected, the rate is $34 \%$ in Western countries and $19 \%$ in Japan. Although we should be very cautious in any comparison of mortality rates between two different 
populations, since there are several potential confounders, such as differences in medical insurance systems among the various countries, it is important to be aware that there are dramatic differences in mortality between countries with therapeutic interventions such as anti-coagulation therapy for septic DIC and countries without.

Protocol-related differences in in-hospital mortality rates of patients with septic DIC within Japan

As we have mentioned, international comparisons of mortality rates can be problematic due to differences between the populations and healthcare systems involved. The impact of population-related confounders can be reduced, and more meaningful comparisons can be obtained, by comparing mortality rates among hospitals that are within the same country but that operate according to different treatment protocols. The fact that some institutions in Japan perform anti-coagulation treatments while others do not has enabled us to evaluate the effects of anti-coagulation treatments in patients with septic DIC in the clinical setting $(3,4)$. In the present study, we have clearly demonstrated that anti-coagulation therapy for septic DIC patients is associated with reduced in-hospital mortality rates as compared with no such treatments.

\section{Limitations of the present study}

\section{Patient characteristics and sample size}

This study incorporated data obtained from only 40 institutions in Japan, most of which were critical care centers or university hospitals, and the data from such institutions may not be representative of the entire country. Furthermore, the severity of sepsis in patients admitted to such hospitals may be greater than that in patients admitted to local or regional medical centers; in fact, as Table 1 shows, the proportion of patients with APACHE II score greater than 20, indicating a rather severe disease state, was $64.3 \%$ in the present study. Within this patient population, however, we found a significant reduction in in-hospital mortality rate at hospitals that routinely provided anti-coagulation treatments to septic DIC patients.

The total number of patients including non-DIC patients with complete information on both the JAAM criteria and the ISTH criteria was 2513 , which we believe is sufficiently large for an analysis of the association between institutional anti-coagulation therapy protocols and in-hospital mortality.

Furthermore, the variety of institutional criteria for anti-coagulation therapy in Japan, regardless of whether therapy for septic DIC is provided, may improve our ability to evaluate its treatment effect on this type of DIC.

If compared with patients who were excluded because of incomplete data for score calculation for JAAM and ISTH, such excluded patients were more likely to be younger, have more SOFA score changing by $\geq 2$, and higher APACHE II scores.

Rate of anti-coagulation therapy administration in each group 
Table 2 shows the rate at which anti-coagulation therapy was administered in each group. The differences in this rate among the three groups (NO-TX, DO-TX and DEP-TX) were dramatic: in JAAM-DIC patients, anti-coagulation treatment was given to $10.6 \%$ of patients in NO-TX hospitals, $73.4 \%$ of patients in DO-TX hospitals, and $54.3 \%$ of patients in DEP-TX hospitals. Even in NO-TX hospitals, a small percentage of DIC cases were treated with anti-coagulation therapy. Hospitals were classified into the NOTX group if they self-reported that they did not typically provide anti-coagulation therapy. This classification method could be the most serious limitation of this study. Although the observed huge differences in the proportions of patients who received DIC treatment in each group seem to confirm the validity of the three groups in this study, we need to perform a future RCT study to define effects of institutional anti-coagulation protocol on intra-hospital mortality in septic DIC patients.

\section{Which criteria for septic DIC: JAAM or ISTH?}

In this study, septic DIC patients diagnosed according to the JAAM criteria were also assessed by the ISTH criteria for overt DIC. The JAAM criteria are well established and show very high sensitivity and specificity in diagnosing septic DIC $(19,20,21)$. In general, the ISTH criteria are used to determine overt DIC, while the JAAM criteria are used to diagnose DIC at an earlier, less easily detectable stage. Therefore, ISTH-DIC patients usually have more severe sepsis than JAAM-DIC patients do. In fact, in a validation study of the JAAM-DIC criteria, ISTH-DIC patients have been reported to have more severe sepsis (19). Furthermore, the ISTH-DIC patients in this study were more likely to have more severe APACHE II scores greater than or equal to 30 (data not shown). As we $(12)$ and others $(3,22)$ have reported previously, anticoagulation therapy could be more effective for septic DIC patients with higher severity, such as the ISTHDIC patients in this study. However, as the lower panel of Table 3 shows, when only ISTH-DIC patients were considered, there were no statistically significant differences in in-hospital mortality rate among the three treatment-protocol groups. Possible explanations for this include the limited number of ISTH-DIC cases after patients with incomplete descriptions of the laboratory data needed to calculate ISTH scores were excluded, as well as the possibility of other unknown confounding factors. Nevertheless, as Table 4 shows, we demonstrated clearly that, among ISTH-DIC patients, adjusted HRs of in-hospital mortality were significantly lower in the DO-TX and DEP-TX groups than in the NO-TX group. This matter will need to be clarified in the future.

\section{Conclusions}

The present results support the use of anti-coagulation treatments for septic DIC and suggest that outcomes are affected by other institutional factors besides anti-coagulation protocol, such as an institutional approach to sepsis. The mechanisms underlying this effect should be clarified.

\section{Abbreviations}

APACHE: Acute Physiology and Chronic Health Evaluation; 
AT: Anti-thrombin;

CHDF: Continuous Hemodiafiltration;

DIC: Disseminated Intravascular Coagulation);

ISTH: International Society of Thrombosis and Hemostasis;

JAAM: Japanese Association of Acute Medicine;

MOF: Multi-organ System Failure;

RCT: Randomized Clinical Trial

rh-TM: Human Recombinant Thrombomoduline;

SOFA: Sequential Organ Failure Assessment;

\section{Specific abbreviations of this study:}

HMR: Hazard Ratio of Intra-hospital Mortality Rate;

Three groups of this study depending on DIC treatment protocol:

patients admitted to hospitals providing basically no anti-coagulation therapy (NO-TX group); those admitted to hospitals routinely providing such treatment (anti-thrombin concentrate and/or rhthrombomodulin or other anti-coagulants such as heparin/heparinoids: DO-TX group); and those admitted to hospitals providing treatment at the discretion of the physician-in-charge (DEP-TX group).

\section{Declarations}

\section{Ethics approval and consent to participate}

The J-SEPTIC DIC Study was conducted at 42 intensive care units (ICUs) in 40 institutions in Japan. This study was approved by the Institutional Local Ethics Committee for Clinical Studies at Ehime University Graduate School of Medicine. Furthermore, the Institutional Review Board of each hospital approved the study, and the need for informed consent was waived due to the study's retrospective nature.

\section{Consent for publication}

As stated above, there were no written informed consents available, since which were waived due to the registry study's nature by the IRB.

\section{Funding}

No funding was received for this study. 
Availability of data and materials

The datasets for the current study are available from the corresponding author upon reasonable request.

\section{Authors' contributions}

$\mathrm{KT}$ conceived and designed the study. $\mathrm{KT}, \mathrm{HM}, \mathrm{MO}, \mathrm{SA}$, and YN prepared the data for analysis. KT conducted the data analysis. $\mathrm{HM}, \mathrm{MO}, \mathrm{SA}, \mathrm{YN}$ and $\mathrm{MA}$ assisted with the interpretation of the results and supervised the study. KT and MA drafted the article. All authors read and approved the manuscript. KT and MA take responsibility for the paper as a whole.

\section{Competing interests}

The authors declare that they have no competing interests.

\section{References}

1. Gando S, Levi M, Toh CH, Disseminated intravascular coagulation. Nat Rev Dis Primers. 2: 16037, 2016.

2. Rhodes A, Evans LE, Alhazzani W, Levy MM, Antonelli M, Ferrer R, Kumar A, Sevransky JE, Sprung CL, Nunnally ME, Rochwerg B, Rubenfeld GD, Angus DC, Annane D, Beale RJ, Bellinghan GJ, Bernard GR, Chiche JD, Coopersmith C, De Backer DP, French CJ, Fujishima S, Gerlach H, Hidalgo JL, Hollenberg SM, Jones AE, Karnad DR, Kleinpell RM, Koh Y, Lisboa TC, Machado FR, Marini JJ, Marshall JC, Mazuski JE, Mclntyre LA, McLean AS, Mehta S, Moreno RP, Myburgh J, Navalesi P, Nishida O, Osborn TM, Perner A, Plunkett CM, Ranieri M, Schorr CA, Seckel MA, Seymour CW, Shieh L, Shukri KA, Simpson SQ, Singer M, Thompson BT, Townsend SR, Van der Poll T, Vincent JL, Wiersinga WJ, Zimmerman JL, Dellinger RP. Surviving Sepsis Campaign: International Guidelines for Management of Sepsis and Septic Shock: 2016. Crit Care Med. 2017 Mar; 45(3): 486-552.

3. Hayakawa M, Yamakawa K, Saito S, Uchino S, Kudo D, lizuka Y, Recombinant human soluble thrombomodulin and mortality in sepsis-induced disseminated intravascular coagulation. A multicentre retrospective study. Thromb Haemost. 115: 1157-1166, 2016.

4. Hayakawa, $M$, et al. Nationwide registry of sepsis patients in Japan focused on disseminated intravascular coagulation 2011-2013. Sci Data. 5: 180243 doi: 10.1038/sdata.2018.243 (2018).

5. Singer M, Deutschman CS, Seymour CW, Shankar-Hari M, Annane D, Bauer M, Bellomo R, Bernard GR, Chiche JD, Coopersmith CM, Hotchkiss RS, Levy MM, Marshall JC, Martin GS, Opal SM, Rubenfeld GD, van der Poll T, Vincent JL, Angus DC. The Third International Consensus Definitions for Sepsis and Septic Shock (Sepsis-3). JAMA. 2016 Feb 23; 315(8): 801-810.

6. Levy MM, Fink MP, Marshall JC, Abraham E, Angus D, Cook D, Cohen J, Opal SM, Vincent JL, Ramsay G, Sccm/Esicm/Accp/Ats/Sis, 2001 SCCM/ESICM/ACCP/ATS/SIS International Sepsis Definitions Conference. Critical care medicine, 31: 1250-1256, 2003. 
7. Knaus WA, Draper EA, Wagner DP, Zimmerman JE, APACHE II: a severity of disease classification system. Crit Care Med. 13: 818-829, 1985.

8. Vincent JL, de Mendonca A, Cantraine F, Moreno R, Takala J, Suter PM, Sprung CL, Colardyn F, Blecher S, Use of the SOFA score to assess the incidence of organ dysfunction/failure in intensive care units: results of a multicenter, prospective study. Working group on "sepsis-related problems" of the European Society of Intensive Care Medicine. Crit Care Med. 26: 1793-1800, 1998.

9. Bone RC, Balk RA, Cerra FB, Dellinger RP, Fein AM, Knaus WA, Schein RM, Sibbald WJ, Definitions for sepsis and organ failure and guidelines for the use of innovative therapies in sepsis. The ACCP/SCCM Consensus Conference Committee. American College of Chest Physicians/Society of Critical Care Medicine. Chest. 101: 1644-1655, 1992.

10. Gando S, Iba T, Eguchi Y, Ohtomo Y, Okamoto K, Koseki K, Mayumi T, Murata A, Ikeda T, Ishikura H, Japanese Association for Acute Medicine Disseminated Intravascular Coagulation Study G, A multicenter, prospective validation of disseminated intravascular coagulation diagnostic criteria for critically ill patients: comparing current criteria. Crit Care Med. 34: 625-631, 2006.

11. Taylor FB Jr, Toh CH, Hoots WK, Wada H, Levi M, Towards definition, clinical and laboratory criteria, and a scoring system for disseminated intravascular coagulation. Scientific Subcommittee on Disseminated Intravascular Coagulation (DIC) of the International Society on Thrombosis and Haemostasis (ISTH). Thromb Haemost. 86: 1327-1330, 2001.

12. Tanaka K, Takeba J, Matsumoto H, Ohshita M, Annen S, Moriyama N, Nakabayashi Y, Aibiki M. Anticoagulation therapy using rh-thrombomodulin and/or antithrombin III agent is associated with reduction in in-hospital mortality in septic disseminated intravascular coagulation: A nationwide registry study. Shock. 2019 Jun;51(6):713-717.

13. Dellinger RP, Levy MM, Rhodes A, Annane D, Gerlach H, Opal SM, Sevransky JE, Sprung CL, Douglas IS, Jaeschke R, et. al; Surviving Sepsis Campaign Guidelines Committee including the Pediatric Subgroup. Surviving sepsis campaign: international guidelines for management of severe sepsis and septic shock: 2012. Crit Care Med. 41: 580-637, 2013.

14. Levy MM, Rhodes A, Phillips GS, Townsend SR, Schorr CA, Beale R, Osborn T, Lemeshow S, Chiche JD, Artigas A, Dellinger RP. Surviving Sepsis Campaign: association between performance metrics and outcomes in a 7.5-year study. Crit Care Med. 43: 3-12, 2015.

15. Sawamura A, Hayakawa M, Gando S, Kubota N, Sugano M, Wada T, Katabami K. Application of the Japanese Association for Acute Medicine disseminated intravascular coagulation diagnostic criteria for patients at an early phase of trauma. Thromb Res. 124: 706-710, 2000.

16. Rhodes A, Evans LE, Alhazzani W, Levy MM, Antonelli M, Ferrer R, Kumar A, Sevransky JE, Sprung CL, Nunnally ME, et., al. Surviving Sepsis Campaign: International Guidelines for Management of Sepsis and Septic Shock: 2016. Crit Care Med. 45: 486-552, 2017.

17. Levy MM, Dellinger RP, Townsend SR, Linde-Zwirble WT, Marshall JC, Bion J, Schorr C, Artigas A, Ramsay G, Beale R, et al.; Surviving Sepsis Campaign, The Surviving Sepsis Campaign: Results of an 
international guideline based performance improvement program targeting severe sepsis. Crit Care Med. 38: 367-374, 2010.

18. Ogura H, Gando S, Saitoh D, Takeyama N, Kushimoto S, Fujishima S, Mayumi T, Araki T, Ikeda H, Kotani J, et al.; Japanese Association for Acute Medicine Sepsis Registry (JAAMSR) Study Group, Epidemiology of severe sepsis in Japanese intensive care units: a prospective multicenter study. $\mathrm{J}$ Infect Chemother. 20: 157-162, 2014.

19. Gando S, Iba T, Eguchi Y, Ohtomo Y, Okamoto K, Koseki K, Mayumi T, Murata A, Ikeda T, Ishikura H; Japanese Association for Acute Medicine Disseminated Intravascular Coagulation (JAAM DIC) Study Group, A multicenter, prospective validation of disseminated intravascular coagulation diagnostic criteria for critically ill patients: comparing current criteria. Crit Care Med. 34: 625-631, 2006.

20. Gando S, Saitoh D, Ogura H, Mayumi T, Koseki K, Ikeda T, Ishikura H, Iba T, Ueyama M, Eguchi Y, et al.; Japanese Association for Acute Medicine Disseminated Intravascular Coagulation (JAAM DIC) Study Group, Disseminated intravascular coagulation (DIC) diagnosed based on the Japanese Association for Acute Medicine criteria is a dependent continuum to overt DIC in patients with sepsis. Thromb Res. 123: 715-718, 2009.

21. Gando S, Saitoh D, Ogura H, Fujishima S, Mayumi T, Araki T, Ikeda H, Kotani J, Kushimoto S, Miki Y, et al.; Japanese Association for Acute Medicine Sepsis Registry Study Group, A multicenter, prospective validation study of the Japanese Association for Acute Medicine disseminated intravascular coagulation scoring system in patients with severe sepsis. Crit Care. 17: R111, 2013. s

\section{Tables}

Table 1. Background of Patients in NO-, DO- and DEP-TX Groups 


\begin{tabular}{|c|c|c|c|c|c|}
\hline & All patients & NO-TX & DO-TX & DEP-TX & \\
\hline & $(n=2513)$ & $(n=287)$ & $(n=1632)$ & $(n=594)$ & P-value \\
\hline Male sex & $1508(60.1)$ & $184(64.1)$ & 974 (59.7) & 350 (58.9) & 0.30 \\
\hline Age (mean \pm SD) & $68.8 \pm 14.6$ & $68.2 \pm 14.2$ & $68.6 \pm 14.7$ & $69.4 \pm 14.5$ & 0.40 \\
\hline Change in SOFA & & & & & 0.29 \\
\hline$\geq 2$ & $626(24.9)$ & $61(21.3)$ & $411(25.2)$ & $154(25.9)$ & \\
\hline \multicolumn{6}{|l|}{ APACHE II score } \\
\hline$<20$ & 897 (35.7) & $91(31.7)$ & $591(36.2)$ & $215(36.2)$ & 0.20 \\
\hline $20-29$ & 1055 (42.0) & $120(41.8)$ & 697 (42.7) & $238(40.1)$ & \\
\hline$\geq 30$ & $561(22.3)$ & $76(26.5)$ & $344(21.1)$ & $141(23.7)$ & \\
\hline \multicolumn{6}{|l|}{ Infection site } \\
\hline Respiratory & $648(25.8)$ & $84(29.3)$ & $447(27.4)$ & 117 (19.7) & 0.0004 \\
\hline Abdominal & 817 (32.5) & $72(25.1)$ & $523(32.1)$ & $222(37.4)$ & 0.001 \\
\hline Soft tissue & $322(12.8)$ & $36(12.5)$ & 201 (12.3) & 85 (14.3) & 0.46 \\
\hline Urinary tract & $386(15.4)$ & $42(14.6)$ & $263(16.1)$ & $81(13.6)$ & 0.33 \\
\hline Other/unknown & 340 (13.5) & $53(18.5)$ & $198(12.1)$ & $89(15.0)$ & 0.008 \\
\hline \multicolumn{6}{|l|}{ Basal Disease } \\
\hline None & $1686(67.1)$ & $181(63.1)$ & 1078 (66.1) & 427 (71.9) & 0.01 \\
\hline Liver & $88(3.5)$ & $11(3.8)$ & $62(3.8)$ & $15(2.5)$ & 0.33 \\
\hline Lung & $59(2.4)$ & $6(2.1)$ & $39(2.4)$ & $14(2.4)$ & 0.95 \\
\hline Heart & 98 (3.9) & $0(0.0)$ & $80(4.9)$ & $18(3.0)$ & 0.0002 \\
\hline Kidney & $145(5.8)$ & $28(9.8)$ & $91(5.6)$ & $26(4.4)$ & 0.005 \\
\hline Immune (compromised) & $329(13.1)$ & $55(19.2)$ & $197(12.1)$ & $77(13.0)$ & 0.005 \\
\hline$\geq 2$ organs & $108(4.3)$ & $6(2.1)$ & $85(5.2)$ & $17(2.9)$ & 0.008 \\
\hline \multicolumn{6}{|l|}{ CHDF } \\
\hline None & $1623(64.6)$ & $217(75.6)$ & $1032(63.2)$ & $374(63.0)$ & 0.0002 \\
\hline Renal RRT & $659(26.2)$ & $69(24.0)$ & $448(27.5)$ & $142(23.9)$ & 0.16 \\
\hline Non-renal RRT & $131(5.2)$ & $1(0.4)$ & $68(4.2)$ & $62(10.4)$ & $<0.0001$ \\
\hline Both & $100(4.0)$ & $0(0.0)$ & $84(5.2)$ & $16(2.7)$ & $<0.0001$ \\
\hline
\end{tabular}




\begin{tabular}{|llllll|} 
Hemostatic abnormality & $428(17.0)$ & $77(26.8)$ & $280(17.2)$ & $71(12.0)$ & $<0.0001$ \\
\hline Treatment of original infection & $1073(42.7)$ & $99(34.5)$ & $687(42.1)$ & $287(48.3)$ & 0.0004 \\
\hline Ventilator application & $1845(73.4)$ & $181(63.1)$ & $1240(76.0)$ & $424(71.4)$ & $<0.0001$ \\
\hline Blood purification & $981(39.0)$ & $80(27.9)$ & $655(40.1)$ & $246(41.4)$ & 0.0002 \\
\hline Vasopressor use & $1959(78.0)$ & $222(77.4)$ & $1280(78.4)$ & $457(76.9)$ & 0.73 \\
\hline
\end{tabular}

Table 2. Rates of DIC Treatment according to Group

\begin{tabular}{|c|c|c|c|c|}
\hline \multicolumn{5}{|l|}{ All $(n=2513)$} \\
\hline $\begin{array}{l}\text { DIC Treatment } \\
\text { Protocol }\end{array}$ & $\begin{array}{l}\text { No } \\
\text { therapy }\end{array}$ & $\begin{array}{l}\text { AT and/or } \\
\text { TM only }\end{array}$ & $\begin{array}{l}\text { AT and/or TM with other anti- } \\
\text { coagulants }\end{array}$ & $\begin{array}{l}\text { Other anti- } \\
\text { coagulants only }\end{array}$ \\
\hline NO-TX $(n=287)$ & $\begin{array}{l}265 \\
(92.3)\end{array}$ & $19(6.6)$ & $2(0.7)$ & $1(0.4)$ \\
\hline DO-TX $(n=1632)$ & $\begin{array}{l}617 \\
(37.8)\end{array}$ & $693(42.5)$ & $240(14.7)$ & $82(5.0)$ \\
\hline DEP-TX $(n=594)$ & $\begin{array}{l}324 \\
(54.6)\end{array}$ & $173(29.1)$ & $63(10.6)$ & $34(5.7$ \\
\hline \multicolumn{5}{|l|}{ JAAM ( $n=1856)$} \\
\hline $\begin{array}{l}\text { DIC Treatment } \\
\text { Protocol }\end{array}$ & $\begin{array}{l}\text { No } \\
\text { therapy }\end{array}$ & $\begin{array}{l}\text { AT and/or } \\
\text { TM only }\end{array}$ & $\begin{array}{l}\text { AT and/or TM with other anti- } \\
\text { coagulants }\end{array}$ & $\begin{array}{l}\text { Other anti- } \\
\text { coagulants only }\end{array}$ \\
\hline NO-TX $(n=208)$ & $\begin{array}{l}186 \\
(89.4)\end{array}$ & $19(9.1)$ & $2(1.0)$ & $1(0.5)$ \\
\hline DO-TX $(n=1202)$ & $\begin{array}{l}314 \\
(26.1)\end{array}$ & $617(51.3)$ & $217(18.1)$ & $54(4.5)$ \\
\hline DEP-TX $(n=446)$ & $\begin{array}{l}204 \\
(45.7)\end{array}$ & 157 (35.2) & $57(12.8)$ & $28(6.3)$ \\
\hline \multicolumn{5}{|l|}{ ISTH $(n=1089)$} \\
\hline $\begin{array}{l}\text { DIC Treatment } \\
\text { Protocol }\end{array}$ & $\begin{array}{l}\text { No } \\
\text { therapy }\end{array}$ & $\begin{array}{l}\text { AT and/or } \\
\text { TM only }\end{array}$ & $\begin{array}{l}\text { AT and/or TM with other anti- } \\
\text { coagulants }\end{array}$ & $\begin{array}{l}\text { Other anti- } \\
\text { coagulants only }\end{array}$ \\
\hline NO-TX $(n=116)$ & $\begin{array}{l}100 \\
(86.2)\end{array}$ & 15 (12.9) & $1(0.9)$ & $0(0.0)$ \\
\hline DO-TX $(n=710)$ & $\begin{array}{l}136 \\
(19.2)\end{array}$ & $393(55.4)$ & 154 (21.7) & $27(3.8)$ \\
\hline DEP-TX $(n=263)$ & $\begin{array}{l}92 \\
(35.0)\end{array}$ & $111842.2)$ & 43 (16.4) & $17(6.5)$ \\
\hline
\end{tabular}


Table 3. APACHE II Scores and Hospital Mortality Rate in Each Group 


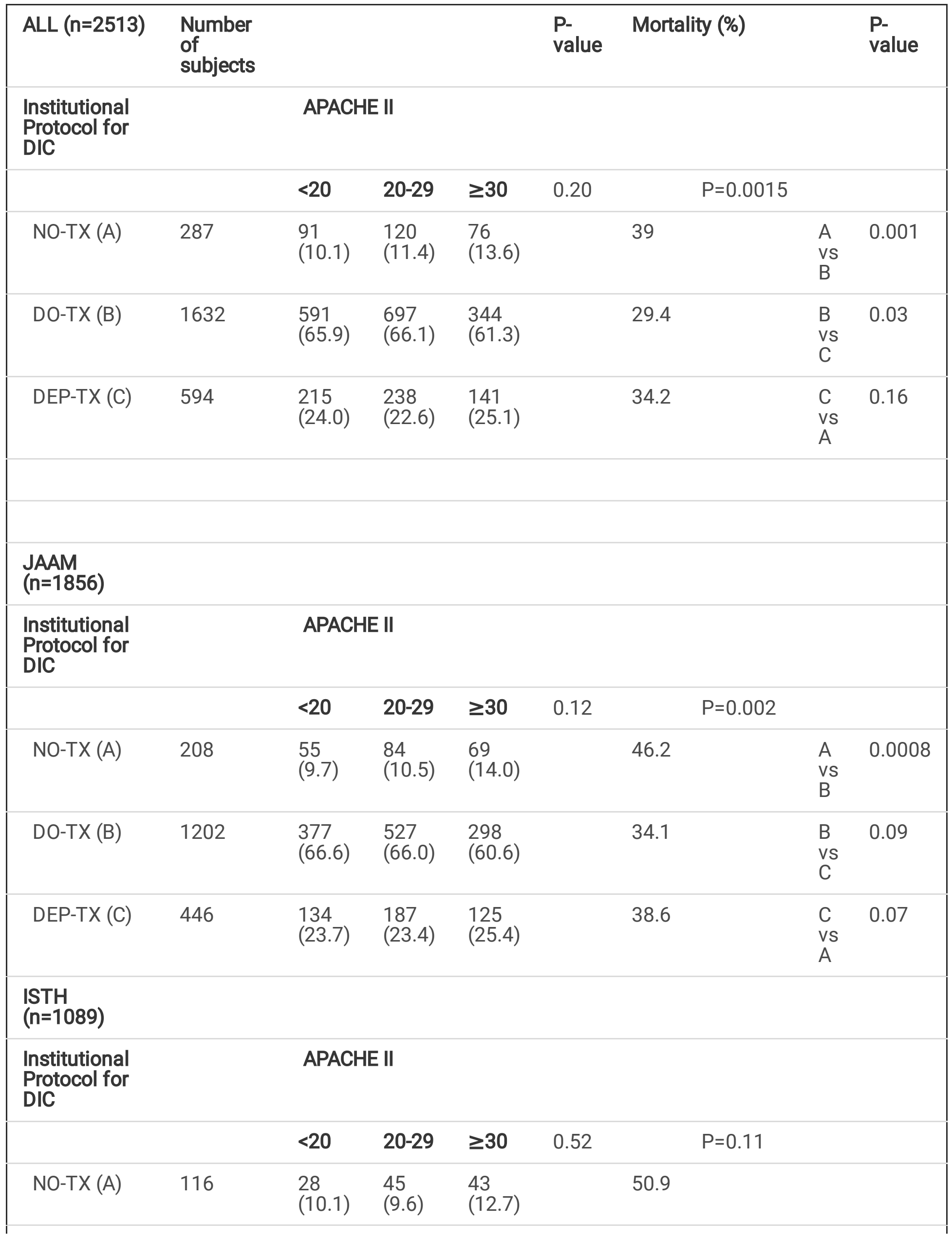




\begin{tabular}{|llllll|} 
DO-TX (B) & 710 & 180 & 318 & 212 & 40.6 \\
& & $(64.8)$ & $(67.5)$ & $(62.4)$ & \\
\hline DEP-TX (C) & 263 & 70 & 108 & 85 & 42.2 \\
& & $(25.2)$ & $(22.9)$ & $(25.0)$ & \\
\hline
\end{tabular}

Table 4. Multi-Variable Analyses of In-Hospital Mortality among Groups

\begin{tabular}{|c|c|c|c|c|}
\hline ALL $(n=2513)$ & Adjusted HR* & \multicolumn{2}{|c|}{$95 \% \mathrm{Cl}$} & P-value \\
\hline \multicolumn{5}{|c|}{ DIC Treatment Protocol } \\
\hline NO-TX & \multicolumn{4}{|l|}{1.00} \\
\hline DO-TX & 0.84 & 0.68 & 1.05 & 0.12 \\
\hline DEP-TX & 0.96 & 0.75 & 1.22 & 0.72 \\
\hline JAAM $(n=1856)$ & Adjusted HR* & \multicolumn{2}{|c|}{$95 \% \mathrm{Cl}$} & P-value \\
\hline \multicolumn{5}{|c|}{ DIC Treatment Protocol } \\
\hline NO-TX & \multicolumn{4}{|l|}{1.00} \\
\hline DO-TX & 0.76 & 0.60 & 0.96 & 0.02 \\
\hline DEP-TX & 0.84 & 0.65 & 1.09 & 0.84 \\
\hline ISTH $(n=1089)$ & Adjusted HR* & $95 \% \mathrm{C}$ & & P-value \\
\hline \multicolumn{5}{|c|}{ DIC Treatment Protocol } \\
\hline NO-TX & \multicolumn{4}{|l|}{1.00} \\
\hline DO-TX & 0.70 & 0.52 & 0.95 & 0.02 \\
\hline DEP-TX & 0.69 & 0.49 & 0.97 & 0.03 \\
\hline \multicolumn{5}{|c|}{ *Adjusted for sex, age(continuous), changes in SOFA, } \\
\hline \multicolumn{5}{|c|}{ APACHE II score, infection site, basal disease, CHDF, } \\
\hline \multicolumn{5}{|c|}{ hemostatic abnormality, treatment of initial infection, } \\
\hline
\end{tabular}

